\title{
Complications of pregnancy and benign familial joint hyperlaxity
}

\author{
J G THORNTON, ${ }^{1}$ J HILL, ${ }^{2}$ AND H A BIRD ${ }^{2}$
}

From the ${ }^{1}$ Department of Obstetrics and Gynaecology, General Infirmary, Leeds; and the ${ }^{2}$ Rheumatism $\vec{\circ}$ Research Unit, Department of Medicine, University of Leeds, Leeds

SUMMARY A family is described in which four generations were affected by benign familial joint妾 hyperlaxity and, in the two generations for which obstetric data were available, pregnancies werei complicated by unexplained mid-trimester vaginal bleeding. This prompted a study to determine whether unexplained antepartum haemorrhage (APH) and premature rupture of the membranes (PROM) both of which might reflect the structure of fetal collagen, were associated with joint ${ }^{?}$ hyperlaxity in offspring. The joint hyperlaxity of children born from such pregnancies was slightlys greater than that found in age matched children born from uncomplicated pregnancies.

Key words: hypermobility (joint), labour (premature), abortion (threatened), abruptiogo placentae.

Early case histories suggested that the EhlersDanlos syndrome (EDS) was associated with obstetric abnormalities. ${ }^{2}$ More comprehensive surveys showed a clear link between premature labour, PROM, and EDS in the fetus..$^{3-5}$ In 1969 Beighton showed that the variant of EDS usually associated with PROM was type I. ${ }^{6}$ This is one of the variants of this syndrome in which a clear abnormality of collagen has been identified. ${ }^{7}$

Some variants of the EDS are characterised by extreme vascular abnormality, particularly aneurysm formation. Other variants, such as type III, are characterised by minimal vascular change but pronounced peripheral joint hyperlaxity. The distinction between type III EDS and benign familial joint hyperlaxity is somewhat blurred. Joint hyperlaxity is associated with collagen laxity at other sites, and an increased incidence of mitral valve prolapse $^{8}$ and of uterine prolapse ${ }^{9}$ have been described in association with benign joint hyperlaxity.

The bruising seen in patients with EDS is felt to be related to vessel wall fragility. There are isolated reports of pregnancies where the mother, and possibly the fetus, had EDS ${ }^{4}{ }^{10}$ or benign hypermobility, ${ }^{11}$ in which pregnancy was complicated by APH. The placenta is made up of fetal blood in

Accepted for publication 12 August 1987.

Correspondence to Dr J G Thornton, Department of Obstetrics and Gynaecology, Clarendon Wing, The General Infirmary, Belmont Grove, Leeds LS2 9NS. vessels composed of fetal connective tissue and alsō contains maternal blood in the intervillous spaces.0 The possibility that APH may be associated with joint hyperlaxity in the offspring was suggested to ust by the following case history which prompted as more comprehensive study of the association between APH and PROM and familial joint hyperlaxity.

\section{Patients and methods}

INDEX CASE HISTORY

The index case, a 30 year old woman, presented in her sixth pregnancy with recurrent painless vagina bleeding at 10,19 , and 21 weeks necessitating prolonged hospital admission. The placenta waos situated in the upper uterine segment and there was. no local cervical lesion. Her second pregnancy had ended in spontaneous abortion at eight weeks an\% her other four pregnancies had all been complicate $\$$ by mid-trimester bleeding as shown in Fig. 1. Shew was hypermobile and when the Beighton variant 12 of the Carter and Wilkinson scoring system ${ }^{13}$ was applied she had a score of 7/9. Although her tw brothers were unable to attend for assessment of ${ }^{+}$ joint laxity, one aged 40 had a history of recurrent dislocation of the patella and the other aged 3\% wrote to report that he was 'double jointed'. HeP three eldest children had peripheral joint laxity scores of $3 / 9,7 / 9$, and $6 / 9$. The mother of the inde case was also hypermobile and when reviewed irg 
clinic had a score of $7 / 9$ at the age of 62 . She had experienced bleeding in all her three pregnancies. Although the grandmother was dead, she was reported to have been 'very mobile', though no details of her obstetric history were available. None of the family members examined had any other stigmata of connective tissue disease such as cutaneous hyperlaxity or marfanoid habitus.

\section{SURVEY OF OTHER FAMILIES}

To determine whether this family was an isolated example, or whether this represented a more general association between benign familial joint hyperlaxity and APH or PROM, we performed a more systematic survey. Pregnancies recorded during the previous 15 years in the Yorkshire area which had been complicated by unexplained APH or PROM were identified from the obstetric records of hospitals in Yorkshire. Unexplained APH was defined as significant bleeding occurring after the 28th week of pregnancy for which no cause was found. Patients with placenta previa and obvious placental abruption were excluded, but those with possible marginal abruption were included. PROM was defined as rupture of the membranes occurring before the onset of regular contractions and before 35 completed weeks' gestation. Mothers in whom APH or PROM was identified were asked by letter if they would be willing to bring the child resulting from the complicated pregnancy to a rheumatology clinic for assessment of joint laxity. The joint laxity of the child was then measured by the Beighton
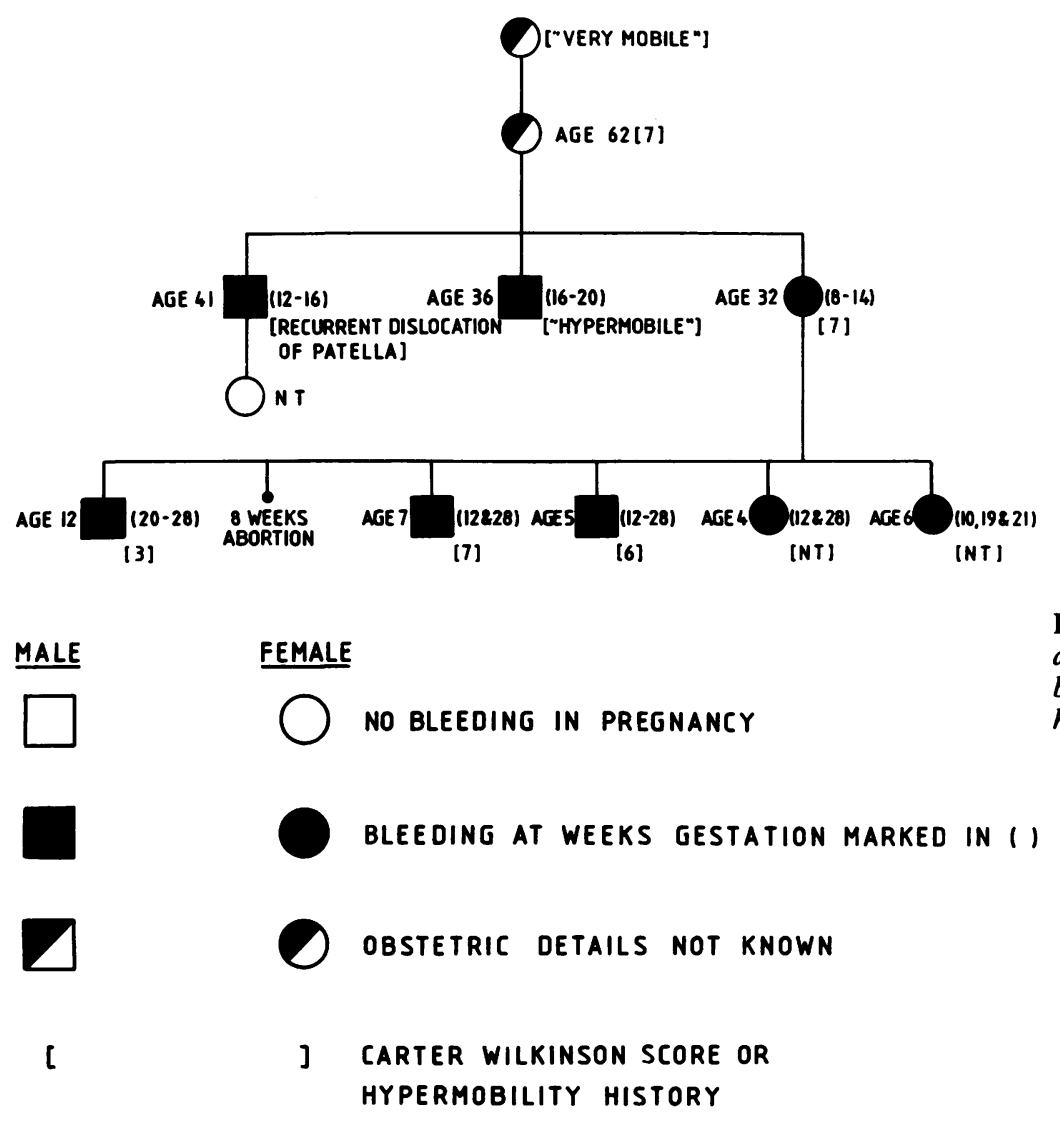

Fig. 1 Family tree demonstrating association between mid-trimester bleeding in pregnancy and familial hyperlaxity. 
modification $^{12}$ of the Carter and Wilkinson scoring system. ${ }^{13}$

A control group approximately matched for age was recruited from local schools. These individuals were assessed for peripheral joint laxity by the same method, it being assumed that these subjects were born from uncomplicated pregnancies. This assumption was felt to be justified as the accepted prevalence in a normal population varies from 1 in 100 to 1 in 500 for unexplained $\mathrm{APH}$ and 1 in 50 to 1 in 300 for PROM before the onset of premature labour.

\section{Results}

As a result of our survey 14 children were identified who had been born from complicated pregnancies, were still living in the Yorkshire area, and whose mothers were agreeable to their attending clinic. Table 1 shows the joint laxity scores for the nine

Table 1 Joint laxity scores for children resulting from pregnancies complicated by premature rupture of the membranes

\begin{tabular}{rll}
\hline Age & Sex & Carter Wilkinson score \\
\hline 12 & F & $2 / 9$ \\
9 & M & $2 / 9$ \\
13 & F & $0 / 9$ \\
10 & M & $4 / 9$ \\
9 & M & $0 / 9$ \\
13 & M & $0 / 9$ \\
10 & M & $4 / 9$ \\
14 & M & $0 / 9$ \\
10 & F & $4 / 9$ \\
\hline
\end{tabular}

Table 2 Joint laxity scores for children resulting from pregnancies complicated by antepartum haemorrhage

\begin{tabular}{lll}
\hline Age & Sex & Carter Wilkinson score \\
\hline 11 & M & $0 / 9$ \\
16 & F & $2 / 9$ \\
13 & M & $4 / 9$ \\
14 & F & $5 / 9$ \\
9 & F & $2 / 9$ \\
\hline
\end{tabular}

children resulting from pregnancies complicated bo PROM and Table 2 the joint laxity scores for the five children resulting from pregnancies complicated by APH. The Carter Wilkinson score was $4 / 9$ of more for $3 / 9$ children resulting from pregnancie complicated by PROM and for $2 / 5$ children resulting from pregnancies complicated by APH. Table 9 compares the distribution of joint laxity in these two populations with approximate age matched controt groups of similar sex distribution. For both PRON4 and APH there is a tendency for the resulting children to have a more pronounced degree of joing laxity than the age matched control subjects. None of the case or control children had any othei stigmata of connective tissue disease.

\section{Discussion}

The family history shows a previously undescribed association between benign familial hyperlaxity an recurrent unexplained mid-trimester bleeding i $\overline{\bar{\beta}}$ pregnancy. Because of the pronounced hyperlaxit产 throughout the family it is not clear whether the mid-trimester bleeding reflects the maternal hype ${ }^{\circ}$ laxity or the fetal hyperlaxity. The format in whic日 obstetric records are kept in Yorkshire does no easily allow the tracing of children resulting fror other pregnancies that have been complicated bo mid-trimester bleeding. Our more systematic surve concentrated on other possible complications of pregnancy that may reflect abnormal collagen strue ture. A major difficulty was the relatively sma\# number of children we were able to trace resultin from pregnancies complicated by PROM and une plained APH. This reflects the relative rarity of these two conditions. Nevertheless, this rarity allows us to have a considerable degree of confidence that subjects selected for the control group (for whom $\mathbb{f}$ was impossible to trace the obstetric records) were not born from pregnancies associated with these complications. The assessment of joint hyperlaxity in children is not easy, and it is possible that if the children had been examined at a greater age, theiv laxity would have been even more pronounced than that of the normal population. Nevertheless, the

Table 3 Comparison of joint laxity in PROM and APH populations with the joint laxity in age and sex matched contrabs

\begin{tabular}{|c|c|c|c|c|}
\hline & $\begin{array}{l}\text { Age (mean) } \\
\text { (years) }\end{array}$ & $\begin{array}{l}\text { Percentage with } \\
\text { score of } \\
4 / 9 \text { or more }\end{array}$ & $\begin{array}{l}\text { Percentage with } \\
\text { score of } \\
3 / 9 \text { or } 2 / 9\end{array}$ & $\begin{array}{l}\text { Percentage with } \\
\text { score of } \\
1 / 9 \text { or } 0 / 9\end{array}$ \\
\hline PROM (n=9; M6:F3) & $11 \cdot 1$ & $33 \cdot 3$ & $22 \cdot 2$ & $44 \cdot 4$ \\
\hline Control $(n=24 ; M 11: F 13)$ & $10 \cdot 8$ & $20 \cdot 8$ & $33 \cdot 3$ & $45 \cdot 8$ \\
\hline APH $(n=5 ; M 2: F 3)$ & $12 \cdot 6$ & $40 \cdot 0$ & $40 \cdot 0$ & $20 \cdot 0$ \\
\hline Control $(n=34 ;$ M17:F17) & $13 \cdot 0$ & $26 \cdot 5$ & $47 \cdot 0$ & $26 \cdot 5$ \\
\hline
\end{tabular}


comparison with age matched controls still suggests the tendency for hyperlaxity to be more pronounced in the offspring of pregnancies complicated by PROM and APH.

Collagen structure is unlikely to be the only single factor in the pathogenesis of PROM and APH. On this basis we would not anticipate a strikingly high correlation between the abnormal pregnancies and this single pathogenetic factor. Indeed, not all have shown a convincing association between PROM and fetal membrane strength, ${ }^{14-16}$ though methods for measuring this vary. Some have shown a firmer adherence between amnion and chorion in prematurely ruptured membranes and suggested a possible mechanism for this association. ${ }^{17}$ Others have shown reduced elasticity in prematurely ruptured membranes. ${ }^{18}$ Other factors will have influence on the pressure to which membranes are subjected and local infection is conventionally held to be among the most common of the environmental factors that may contribute.

Against this background, a study on the relatively small number of subjects available to us is unlikely to be conclusive, though we feel our results provide some support for an association between familial benign joint hyperlaxity in the child and PROM and APH. They also suggest that the association between hyperlaxity and mid-trimester bleeding would be worthy of further study.

We wish to thank the teachers and pupils of Western primary school, Harrogate and Salendine Nook high school, Huddersfield, for their help in providing us with control subjects. We also thank Mrs D K Smith for secretarial help.

\section{References}

1 Benjamin B, Weiner H. Syndrome of cutancous fragility and hyperelasticity and articular hyperlaxity. Am J Dis Child 1943; 65: 247-57.

2 Kanof A. Ehlers-Danlos syndrome: report of a case with suggestion of a possible causal mechanism. Am J Dis Child 1952; 83: 197-202.

3 Barabas A P. Ehlers-Danlos syndrome; associated with prematurity and premature rupture of foetal membranes: possible increase in incidence. $\mathrm{Br}$ Med $J$ 1966; ii: 682-4.

4 Beighton P. Price A, Lord J, Dickson E. Variants of the Ehlers-Danlos Syndrome. Clinical, biochemical, haematological and chromosomal features of 100 patients. Ann Rheum Dis 1969; 28: 228-35.

5 Taylor D J, Wilcox I. Russell J K. Ehlers-Danlos syndrome during pregnancy: a case report and review of the literature. Obstet Gynecol Surv 1981; 36: 277-81.

6 Beighton P. Obstetric aspects of the Ehlers-Danlos syndrome. Journal of Obstetrics and Gynaecology (British Commonwealth) 1969; 76: 97-101.

7 Bird H A. Joint and tissue laxity. In: Wright V, ed. Topical reviews in the rheumatic diseases. Bristol: Wright, 1983.

8 Grahame R, Edwards J H, Pitcher D, Gabell A, Harvey W. A clinical and echocardiographic study of patients with hypermobility syndrome. Ann Rheum Dis 1981; 40: 541-6.

9 Al-Rawi Z S, Al-Rawi Z T. Joint hypermobility in women with genital prolapse. Lancet 1982; i: 1439-41.

10 Mukerji S. Ehlers-Danlos syndrome with pregnancy. J Indian Med Assoc 1975; 64: 149-51.

11 Beighton P, Grahame R, Bird H. Hypermobility of joints. Berlin: Springer, 1983.

12 Beighton P, Solomon L, Soskolne C L. Joint mobility in an African population. Ann Rheum Dis 1973; 32: 413-8.

13 Carter C, Wilkinson J. Persistent joint laxity and congenital dislocation of the hip. J Bone Joint Surg [Br] 1964; 46B: 40-5.

14 Danforth D N, McElin W, States M N. Studies on fetal membranes. Am J Obstet Gynecol 1953; 65: 480-90.

15 Embrey M P. On the strength of the fetal membranes. Journal of Obstetrics and Gynaecology (British Empire) 1954; 61: 793-6.

16 Polishuk W Z, Kohane S, Hadar A. Fetal weight and membrane tensile strength. Am J Obstet Gynecol 1964; 88: 247-50.

17 Meudt R, Meudt E. Rupture of the fetal membranes: an experimental, clinical and histological study. Am J Obstet Gynecol 1967; 99: 562-8.

18 Artal R, Sokol R J, Newman M, Burstein A H, Stojkov J. The mechanical properties of prematurely and nonprematurely ruptured membranes. Am J Obstet Gynecol 1976; 125: 655-9. 